\title{
Basal cell adenocarcinoma of the nasopharyngeal minor salivary glands: a case report and review of the literature
}

Jia Jin ${ }^{1}$ and Xia-Yun $\mathrm{He}^{2^{*}}$

\begin{abstract}
Background: Basal cell adenocarcinomas (BCACs) arise from the minor salivary glands in the upper respiratory tract and are extremely rare. In this report, we present an unusual case of a 57-year-old male with BCAC that arose from the nasopharynx. To our knowledge, this is the first case report of nasopharyngeal BCAC.

Case presentation: In August 2010, a 57-year-old Chinese male presented with epistaxis and decreased hearing for 1 month. He was diagnosed with BCAC of the solid type that arose from the nasopharynx. The patient received radiotherapy alone and exhibited a complete response. A follow-up at 72 months did not detect any evidence of disease recurrence or metastasis. A comprehensive literature review revealed only 7 previously reported cases of $B C A C$ in the upper respiratory tract. Surgery is the first choice to treat BCAC but may impair maxillofacial function. Radiotherapy is reserved for inoperable cases.

Conclusions: Radiotherapy can achieve good local control and preserve maxillofacial function; therefore, this treatment may be a suitable option for patients who are not good candidates for surgery.
\end{abstract}

Keywords: Basal cell adenocarcinoma, Nasopharynx, Radiotherapy, Minor salivary glands

\section{Background}

Basal cell adenocarcinoma (BCAC) of the salivary gland is a rarely diagnosed subtype of all salivary gland neoplasms (1.6\%), representing $2.9 \%$ of all malignant neoplasms [1]. In the latest World Health Organization (WHO) classification, BCAC was defined as a low-grade salivary malignancy with favourable prognosis $[2,3]$. Most BCACs arise from the parotid gland $(>80 \%)$, whereas others originate from the sublingual and submandibular glands. Minor salivary glands are most frequently found in the buccal mucosa and hard palate and are less commonly found in BCAC. The involvement of the upper respiratory tract is rare [4-6]. In this report, we present an unusual case of a 57-year-old male with $\mathrm{BCAC}$ that arose from the nasopharynx. We describe the clinicopathological features, the immunophenotype and the treatment choices with a review of several case reports in the literature. To our knowledge, this was the first case

\footnotetext{
* Correspondence: hexiayun112001@126.com

${ }^{2}$ Department of Radiation Oncology, Fudan University Shanghai Cancer Center, 270 Dong An Road, Shanghai 200032, People's Republic of China Full list of author information is available at the end of the article
}

of BCAC that arose from the minor salivary glands in the nasopharynx.

\section{Case presentation}

In August 2010, a 57-year-old Chinese male presented with epistaxis and decreased hearing for 1 month. No additional symptoms, such as a neck mass, nasal obstruction, headache, diplopia or other cranial nerve palsies, were noted. The patient had no history of previous or synchronous tumours or any family history of cancer. Nasopharyngoscopy revealed a large exophytic tumour that was covered by smooth mucosa, which grew from the right posterolateral nasopharyngeal wall in the right posterior naris. Magnetic resonance imaging (MRI) scans of the nasopharynx and neck using gadolinium enhancement demonstrated a $2.0 \times 1.5 \times 2.0 \mathrm{~cm}$ well enhanced mass over the right posterior nasopharynx with right retropharyngeal node enlargement. The tumour extended across the right parapharyngeal space and infiltrated into the medial pterygoid muscle. In addition, skull base erosion was detected with right alar lamina involvement (Fig. 1a). Cervical lymph node metastasis

(c) The Author(s). 2018 Open Access This article is distributed under the terms of the Creative Commons Attribution 4.0 International License (http://creativecommons.org/licenses/by/4.0/), which permits unrestricted use, distribution, and 

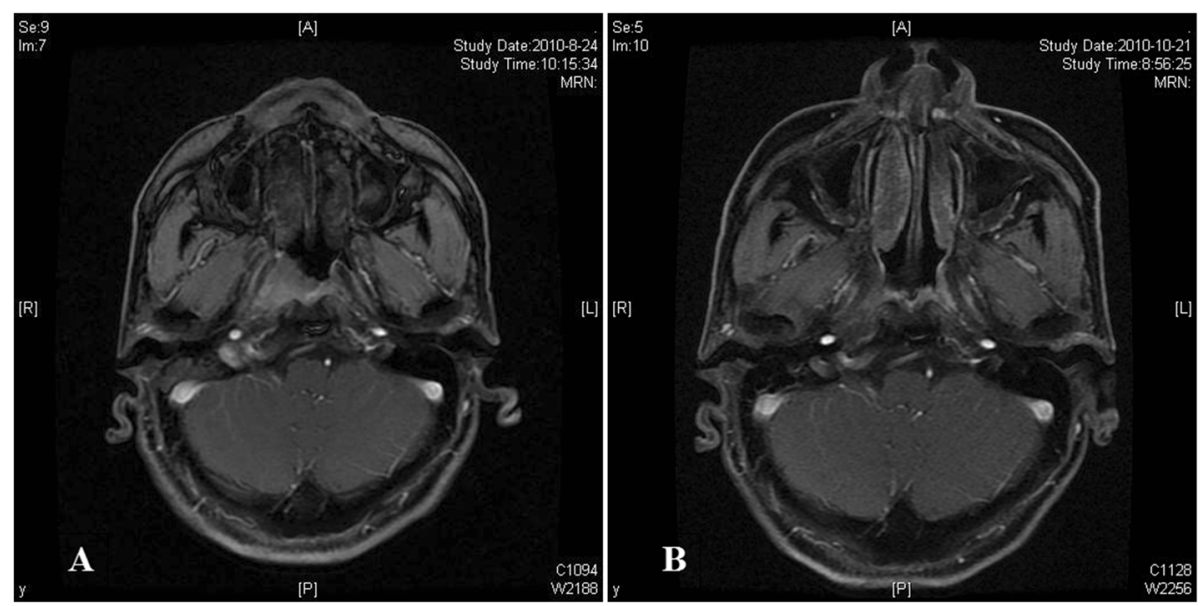

Fig. 1 Axial contrast-enhanced MRI scan. a, MRI scan (2010.8.14) reveals a tumour in the right posterior nasopharynx that extends into the right parapharyngeal space and into the medial pterygoid muscle. b, MRI scan after radiotherapy (2010.10.21) reveals no residual tumour at the primary site

was not observed. Hematologic, hepatic and renal function tests revealed no abnormalities. The patients underwent chest and abdomen computed tomography (CT) as well as a bone scintigram, and no distant metastasis was found. A biopsy of the nasopharynx was performed.

In the biopsy specimen, normal salivary tissue was not present. The tumours were ill demarcated without encapsulation. Tumour cells were arranged in nests and nodules. Two morphologic patterns of the tumour cells were observed. Some small round cells exhibited dark nuclei and scant cytoplasm. Other large cells contained round to oval pale nuclei and eosinophilic to amphophilic cytoplasm. In the central region of the tumour cell nests, large cells displayed a solid growth pattern. Small dark cells were clustered at the periphery of the tumour cell nests and appeared palisaded. Prominent nucleoli and mitosis can be observed, and an average of three mitotic figures were observed per 10 high-power fields (original magnification $\times 400$ ).

In the immunohistochemical analysis, the tumour cells were immunoreactive with P63, vimentin, and cytokeratin (CK7 and CK14) antibodies and focally immunoreactive with a calponin antibody. This case of BCAC was not positive for smooth muscle actin or CD117. The proliferative index as demonstrated by Ki-67 was approximately $10 \%$. Based on the immunohistochemistry results and the pathological findings, which included tumour islands with solid proliferation, basaloid-like cells containing large pale and small dark cells, an infiltrative margin, cellular and nuclear pleomorphism, and prominent mitosis, the patient was diagnosed with a solid-type minor salivary gland BCAC (Fig. 2).

Based on the 2002 American Joint Committee on Cancer (AJCC) Tumor, Node, Metastasis (TNM) staging system [7], the tumour was classified as stage III (T3NOM0).
In our case, the patient received intensity-modulated radiation therapy (IMRT) with $6 \mathrm{MV} \mathrm{X}$-rays. The delineation of the gross tumour volume (GTV) was based on the primary tumour volume determined from the physical and imaging examinations. The clinical target volume (CTV) was defined as the whole nasopharyngeal cavity, the clivus, the skull base, the pterygoid plates, the parapharyngeal space, the sphenoid sinus, the posterior one-third of the nasal cavity, the maxillary sinus, and the drainage of the upper neck (levels II, III, and Va. A total dose of 70.4 Gy/32 F/6.2 W was administered based on the planning target volume (PTVg) (GTV with $0.5 \mathrm{~cm}$ margin). The PTV60 was defined as 60 Gy/30 F (CTV with $0.5 \mathrm{~cm}$ margin) (Fig. 3). After radiotherapy, MRI and nasopharyngoscopy revealed complete disappearance of the tumour (Fig. 1b). The patient was followed up every 3 months for the first 2 years, every 6 months for another 3 years, and then every 12 months. A follow-up at 72 months did not detect any evidence of disease recurrence. The patient developed moderate mucositis as an acute adverse event. However, he did not exhibit any grade 3/4 late adverse events, such as xerostomia, dysgeusia, or hearing impairment.

\section{Discussion}

BCAC that arises from the minor salivary glands in the upper respiratory tract is recognized as an uncommon to rare neoplasm. To our knowledge, only 7 cases have been described in the literature to date [8-10]. Our case is the first case of nasopharyngeal BCAC (Table 1). According to the data in the literature and in this case, this type of tumour predominantly occurs in patients $43-70$ years of age with a mean age of 59 years, and no gender differences (a male-to-female ratio of 1.7:1) were observed. 

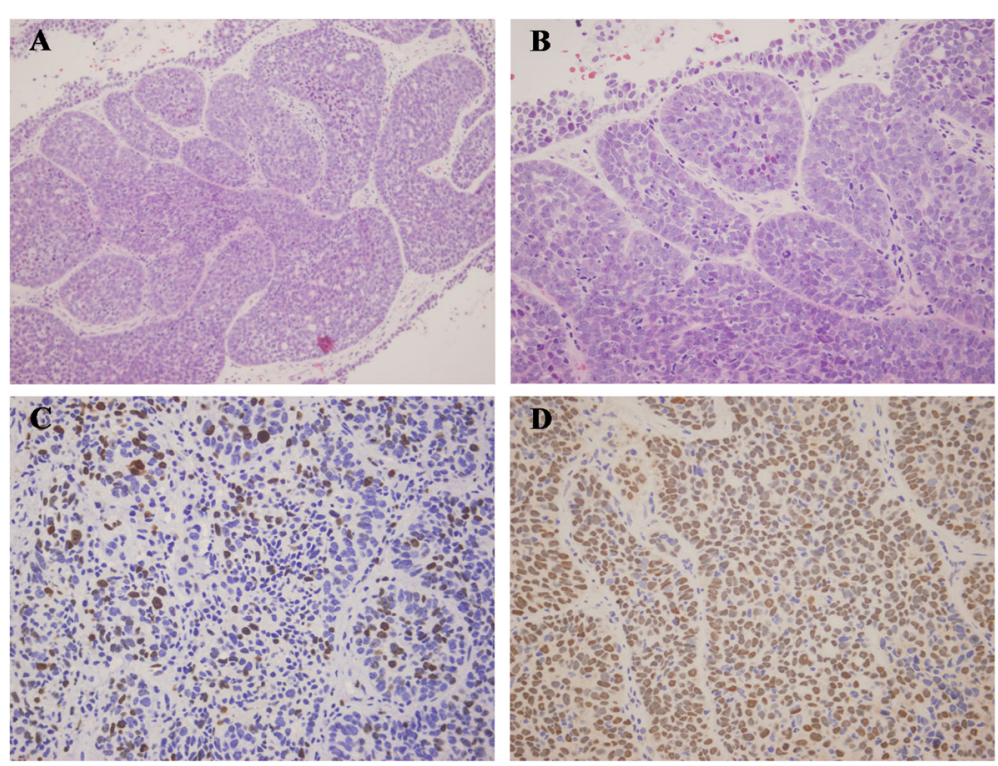

Fig. 2 Haematoxylin-eosin stain and immunohistochemical studies. a, BCAC revealed solid tumour nests with peripheral palisading (haematoxylin and eosin, original magnification $\times 200$ ). b. The tumour cells exhibited apparent cellular pleomorphism and mitotic figures (haematoxylin and eosin, original magnification $\times 400$ ). c, Immunohistochemical staining for Ki-67 demonstrated a proliferative index of approximately $10 \%$ (original magnification $\times 400$ ). $\mathbf{d}$, P63 was strongly expressed by most tumour cells (original magnification $\times 400$ )

Neoplasms with a minor salivary gland origin that arise within the nasopharynx include nasopharyngeal carcinoma (NPC), adenoid hypertrophy, lymphoma, fibroangioma, chordoma, and metastatic tumours. NPC is rarely diagnosed in Western Europe and the United States; however, it is more popular in southern China, southeast
Asia, northern Africa, and Eskimo areas. In the southern regions of the Chinese mainland, the incidence has been estimated as 30 cases/100,000 individuals in endemic areas [11].

Clinical, endoscopic, and imaging examinations cannot distinguish between the pathological types of BCAC;

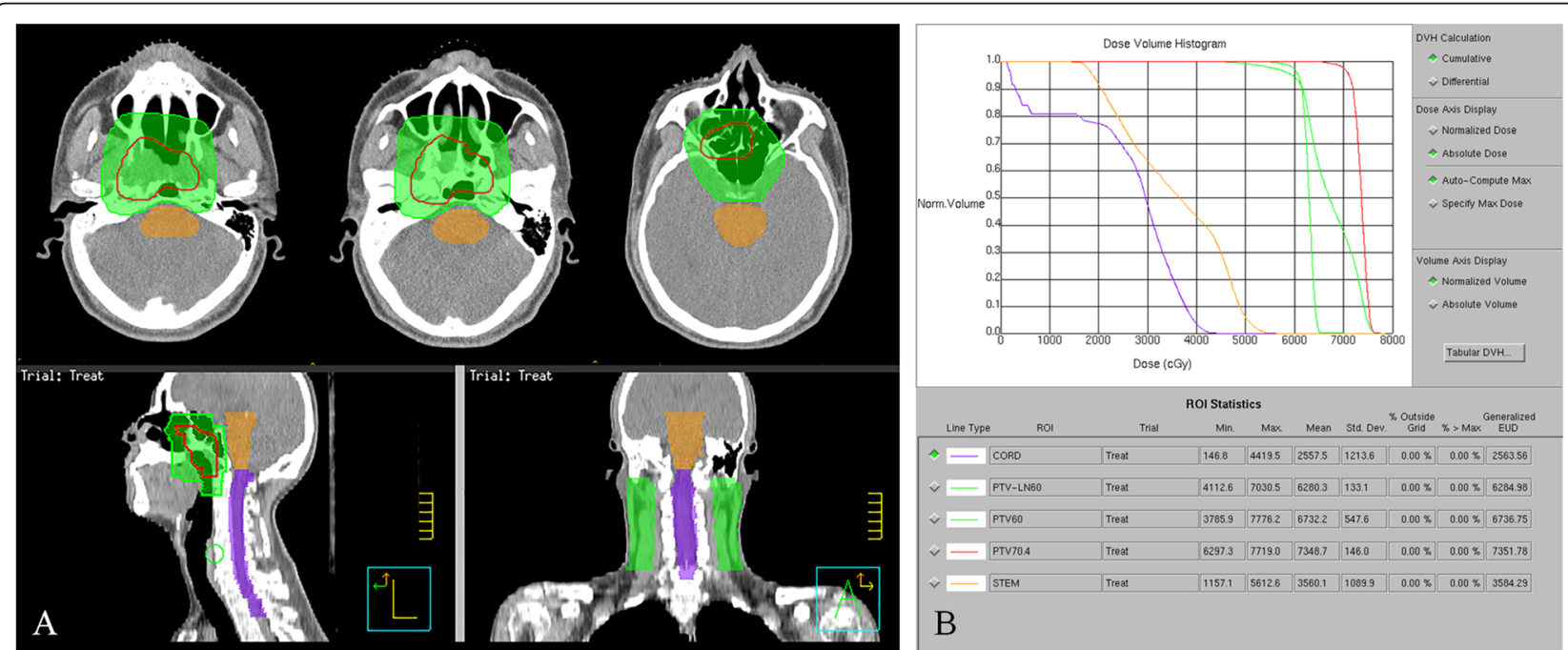

Fig. 3 a, Planning target volume of the gross tumour volume and the high-risk clinical tumour volume. Axial, sagittal and coronal slices representative of this patient's planning target volume (PTV) are presented. Red contour represents PTV of the gross tumour volume to 70.4 Gy, green contour represents PTV of the high-risk clinical tumour volume to $60 \mathrm{~Gy}$, orange contour represents brain stem and purple contour represents spinal cord. $\mathbf{b}$, Dose volume histogram. The dose volume histogram of this patient is presented. The maximum point dose of spinal cord and brain stem are well within the dose constraint. The prescribed dose encompasses at least $95 \%$ of the planning target volume (PTV). None of the PTV receives $\geq 110 \%$ of the prescribed dose 
Table 1 Studies of BCAC of the minor salivary glands in the upper respiratory tract

\begin{tabular}{|c|c|c|c|c|c|c|c|c|c|c|}
\hline Source & Age & Gender & $\begin{array}{l}\text { Tumor } \\
\text { location }\end{array}$ & Tumor Size $(\mathrm{cm})$ & $\begin{array}{l}\text { Histopathological } \\
\text { subtype }\end{array}$ & $\begin{array}{l}\text { Initial } \\
\text { treatment }\end{array}$ & Follow-up & Recurrence & Metastasis & Outcome \\
\hline \multirow[t]{5}{*}{$\begin{array}{l}\text { Fonseca and } \\
\text { Soares, } 1996 \text { [8] }\end{array}$} & 62 & $F$ & Nasal cavity & NA & Solid & $S$ & 4 yrs & Yes & $\begin{array}{l}\text { Yes } \\
\text { (lymph node) }\end{array}$ & DOD \\
\hline & 43 & $F$ & Maxillary sinus & NA & Solid & $S$ & $\begin{array}{l}3 \text { yrs., } \\
6 \text { mos }\end{array}$ & Yes & No & DOD \\
\hline & 66 & M & Maxillary sinus & NA & Solid & S & 3 yrs & No & No & Alive \\
\hline & 56 & $\mathrm{~F}$ & Nasal cavity & NA & Solid & S & $12 \mathrm{yrs}$ & Yes & No & Alive \\
\hline & 52 & M & Ethmoid sinus & NA & Solid & S & 12 mos & Yes & No & Alive \\
\hline $\begin{array}{l}\text { Warrick et al., } \\
2000 \text { [9] }\end{array}$ & 66 & M & Nasal septum & NA & Tubular & $S+R T$ & $\begin{array}{l}1 \text { yrs., } \\
6 \text { mos }\end{array}$ & No & No & Alive (NED) \\
\hline $\begin{array}{l}\text { Jingu et al., } \\
2010 \text { [10] }\end{array}$ & 70 & M & Ethmoid sinus & 5.0 & NA & RT & $\begin{array}{l}1 \mathrm{yrs.} \\
9 \mathrm{mos}\end{array}$ & No & No & Alive (NED) \\
\hline Present case & 57 & M & Nasopharynx & 2.0 & Solid & RT & 6 yrs & No & No & Alive (NED) \\
\hline
\end{tabular}

$F$ female, $M$ male, NA not available, $S$ surgery, $R T$ radiation therapy, NED no evidence of disease, $D O D$ die of disease

therefore, a diagnosis may be difficult during the initial presentation and would be strictly pathological.

BCAC is composed of the following 2 cell types: smaller basaloid cells with scant cytoplasm and dark nuclei and slightly larger polygonal basaloid cells with eosinophilic cytoplasm [5]. Based on the growth pattern, the tumour can be divided into 4 subtypes: solid, trabecular, tubular, and membranous. The most common histomorphologic pattern is the solid type [12, 13]. Several transitions among these histological types may occur within a single tumour, and the subtype classification is based on the predominant pattern $[2,4]$.

Published reports on the immunohistochemical aspects of BCAC have discussed the use of dual myoepithelial markers and epithelial markers [14]. A wide range of immunohistochemical diversity is noted between and within BCAC tumours. Immunostaining of the proliferative fraction (Ki-67) is helpful in distinguishing malignancies from their benign counterparts in salivary gland epithelial tumours. The Ki-67 index is typically $<5 \%$ in benign tumours and $>10 \%$ in malignancies [14].

$\mathrm{BCAC}$ is a low-grade malignancy that tends to recur locally $[15,16]$. Our literature review revealed that approximately half of patients (4 out of $8,50.0 \%$ ) experienced tumour recurrence, and only 1 patient had regional lymph node metastasis. In addition, the mortality rate for this tumour is low. Among 8 patients who were followed up for $0.5-12$ years, 2 patients died of disease approximately 4 wears after diagnosis (Table 1 ).

Treatment of BCAC is well established; however, there are several problems with treatment in clinical practice. Surgical excision with a wide margin to ensure complete tumour removal has been recommended as the mainstay of treatment for BCAC of the major salivary glands. Regional lymph node dissection is indicated only in cases involving cervical lymph nodes [3, 4, 15-17]. BCAC affecting the minor salivary glands are more infiltrative than lesions affecting the major salivary glands [18]. Several surgical approaches have been described, such as an infratemporal approach from the lateral aspect, an antereolateral approach and transpalatal, transmaxillary, and transcervical approaches from the inferior aspect [19]. Radical excision with sufficient healthy margins is difficult mainly due to anatomical boundaries. In addition, postoperative morbidity is considered unacceptable due to the impairment of maxillofacial function in many cases [19].

Radiotherapy is an alternative for inoperable cases after biopsy. Two patients underwent radiotherapy alone due to the anatomical location of the tumour (Table 1). The follow-up indicated that the two cases did not recur or metastasize, and both patients were still alive. The observation period was not long enough (20.9 and 72 months); however, radiotherapy achieved good tumour control.

Most of the previously published studies on BCAC focused on the surgical option and follow-up after surgery, and few studies focused on radiotherapy (Table 1). It is unclear whether radiotherapy is equally as effective as surgery for the management of BCAC. This report contributes to our understanding of the characteristics of $\mathrm{BCAC}$ and the treatment of this disease. Radiotherapy may represent an effective method for patients who are not good candidates for surgery. Future studies, such as small-scale clinical trials, are needed to determine whether radiotherapy is effective for patients with inoperable BCAC.

\section{Conclusions}

This case report is the first published description of $\mathrm{BCAC}$ that arose from the minor salivary glands in the nasopharynx. BCAC is a low-grade malignancy and tends to recur locally. Wide local excision with confirmation of negative margins has been recommend as the first choice for BCAC of the minor salivary glands. Due to the anatomical location of the nasopharynx, radiotherapy alone was an effective method to treat the tumour. The 
patient was followed up for 72 months without any evidence of disease. Radiotherapy can achieve good local control and preserve maxillofacial function; therefore, this treatment may be a suitable option for patients who are not good candidates for surgery.

\section{Abbreviations}

AJCC: the American joint committee on cancer; BCAC: Basal cell adenocarcinoma; CK: Cytokeratin; CT: Computed tomography; CTV: Clinical target volume; DOD: Die of disease; F: Female; GTV: Gross tumour volume; IMRT: Intensity-modulated radiation therapy; M: Male; M: Metastasis; MRI: Magnetic resonance imaging; N: Node; NA: Not available; NED: No evidence of disease; NPC: Nasopharyngeal carcinoma; PTV: Planning target volume; RT: Radiation therapy; S: Surgery; T: Tumour

\section{Funding}

The authors declare that no funding was received for this study.

\section{Availability of data and materials}

The dataset of the current study is available from the corresponding author on reasonable request.

\section{Authors' contributions}

$\mathrm{XH}$ conceived the study, participated in the patient's diagnosis, performed treatment and follow-up and participated in drafting the manuscript. JJ participated in the patient's follow-up, performed the literature research and drafted the manuscript. All authors read and approved the final manuscript.

\section{Ethics approval and consent to participate}

The case report was waived by the Ethics Committee of Fudan University Shanghai Cancer Center. Authors obtained written informed consent and publication consent from the patient.

\section{Consent for publication}

Written informed consent for publication of the clinical details and images was obtained from the patient described in the case report. A copy of the consent form is available for review by the Editor of this journal.

\section{Competing interests}

The authors declare that they have no competing interests.

\section{Publisher's Note}

Springer Nature remains neutral with regard to jurisdictional claims in published maps and institutional affiliations.

\section{Author details}

'Department of Medical Oncology, Fudan University Shanghai Cancer Center, Shanghai 200032, People's Republic of China. ${ }^{2}$ Department of Radiation Oncology, Fudan University Shanghai Cancer Center, 270 Dong An Road, Shanghai 200032, People's Republic of China.

Received: 2 May 2018 Accepted: 6 September 2018

Published online: 10 September 2018

\section{References}

1. Chen KT. Carcinoma arising in monomorphic adenoma of the salivary gland. Am J Otolaryngol. 1985;6(1):39-41. https://doi.org/10.1016/S0196-0709(85)80007-7.

2. Seifert G, Brocheriou C, Cardesa A, Eveson JW. WHO International Histological Classification of Tumours. Tentative Histological Classification of Salivary Gland Tumours. Pathol Res Prac. 1990;186(5):555-81. https://doi.org/10.1016/S0344-0338(11)80220-7.

3. Parashar P, Baron E, Papadimitriou JC, Ord RA, Nikitakis NG. Basal cell adenocarcinoma of the oral minor salivary glands: review of the literature and presentation of two cases. Oral Surg Oral Med Oral Pathol Oral Radiol Endod. 2007;103(1):77-84. https://doi.org/10.1016/j.tripleo.2005.12.021.

4. Skalova A, Michal M, Simpson RH. Newly described salivary gland tumors. Mod Pathol. 2017;30(s1):S27-43. https://doi.org/10.1038/modpathol.2016.167.
5. Jayakrishnan A, Elmalah I, Hussain K, Odell EW. Basal cell adenocarcinoma in minor salivary glands. Histopathology. 2003;42(6):610-4.

https://doi.org/10.1046/j.1365-2559.2003.01651.x.

6. Chen S, Yang S, Chen X. Basal cell adenocarcinoma of the buccal minor salivary gland with liver metastases. Ann Saudi Med. 2015;35(4):318-20. https://doi.org/10.5144/0256-4947.2015.318.

7. Chong VF, Ong CK. Nasopharyngeal carcinoma. Eur J Radiol. 2008;66(3):437-47. https://doi.org/10.1016/j.ejrad.2008.03.029.

8. Fonseca I, Soares J. Basal cell adenocarcinoma of minor salivary and seromucous glands of the head and neck region. Semin Diagn Pathol. 1996; 13(2):128-37.

9. Warrick PD, Irish JC, Mancer K, Dardick I, Pynn BR, Gullane P. Basal cell adenocarcinoma: a rare malignancy of the salivary glands. J Otolaryngol. 2000;29(2):102-9.

10. Jingu K, Hasegawa A, Mizo JE, Bessho H, Morikawa T, Tsuji H, Tsujii H, Kamada T. Carbon ion radiotherapy for basal cell adenocarcinoma of the head and neck: preliminary reportof six cases and review of the literature. Radiat Oncol. 2010;5:89. https://doi.org/10.1186/1748-717X-5-89.

11. He XY, Liu TF, He SQ, Huan SL, Pan ZQ. Late course accelerated hyperfractionated radiotherapy of nasopharyngeal carcinoma (LCAF). Radiother Oncol. 2007;85(1):29-35. https://doi.org/10.1016/j.radonc.2007.08.005.

12. Baddour HM Jr, Fedewa SA, Chen AY. Five- and 10-Year Cause-Specific Survival Rates in Carcinoma of the Minor Salivary Gland. JAMA Otolaryngol Head Neck Surg. 2016;142(1):67-73. https://doi.org/10.1001/jamaoto.2015.2805.

13. Loochtan MJ, Shaar M, Pambuccian S, Borrowdale RW. Subglottic Basal Cell Adenocarcinoma. Ann Otol Rhinol Laryngol. 2016;125(2):169-72. https://doi.org/10.1177/0003489415603720.

14. Yamagata K, Oka K, Yoshida H, Yanagawa T, Onizawa K, Yusa H, Ishikawa A, Okada N. Basal cell adenocarcinoma arising from the minor salivary gland in the soft palate: a case report. Pathol Res Pract. 2006;202(6):475-80. https://doi.org/10.1016/j.prp.2005.12.009.

15. Wilson TC, Robinson RA. Basal cell adenocarcinoma and Basal cell adenoma of the salivary glands: a clinicopathological review of seventy tumors with comparison of morphologic features and growth control indices. Head Neck Pathol. 2015:9(2):205-13. https://doi.org/10.1007/s12105-014-0562-4 Epub 2014 Aug 21.

16. Ward BK, Seethala RR, Barnes EL, Lai SY. Basal cell adenocarcinoma of a hard palate minor salivary gland: case report and review of the literature. Head Neck Oncol. 2009:1:41. https://doi.org/10.1186/1758-3284-1-41.

17. Zhan KY, Lentsch EJ. Basal cell adenocarcinoma of the major salivary glands: A population-level study of 509 cases. Laryngoscope. 2016;126(5): 1086-90. https://doi.org/10.1002/lary.25713.

18. Cuthbertson DW, Raol N, Hicks J, Green L, Parke R. Minor salivary gland basal cell adenocarcinoma: a systematic review and report of a new case. JAMA Otolaryngol Head Neck Surg. 2015;141(3):276-83. https://doi.org/10.1001/jamaoto.2014.3344.

19. Wei WI, Sham JS. Nasopharyngeal carcinoma. Lancet. 2005;36(9476):2041-54 https://doi.org/10.1016/S0140-6736(05)66698-6.

\section{Ready to submit your research? Choose BMC and benefit from:}

- fast, convenient online submission

- thorough peer review by experienced researchers in your field

- rapid publication on acceptance

- support for research data, including large and complex data types

- gold Open Access which fosters wider collaboration and increased citations

- maximum visibility for your research: over $100 \mathrm{M}$ website views per year

At BMC, research is always in progress.

Learn more biomedcentral.com/submissions 